\title{
Evaluating mechanisms of postoperative delirium and cognitive dysfunction following elective spine surgery in elderly patients (CONFESS): study protocol for a prospective observational trial
}

Jonas Müller

Department of Neurosurgery, Universitätsmedizin Greifswald

\section{Stephan Nowak}

Department of Neurosurgery, Universitätsmedizin Greifswald

\section{Maria Dewey}

Department of Neurology, Universitätsmedizin Greifswald

Antje Vogelgesang

Department of Neurology, Universitätsmedizin Greifswald

\section{Bettina von Sarnowski}

Department of Neurology, Universitätsmedizin Greifswald

\section{Eiko Rathmann}

Department of Radiology, Universitätsmedizin Greifswald

\section{Sein Schmidt}

Clinical Research Unit, Charité Campus Mitte, Berlin Institute of Health

\section{Sebastian Rehberg}

Department of Anesthesiology, Evangelisches Klinikum Bethel

\section{Taras Usichenko}

Department of Anesthesiology, Universitätsmedizin Greifswald

\section{Harry Kertscho}

Department of Anesthesiology, Universitätsmedizin Greifswald

\section{Klaus Hahnenkamp}

Department of Anesthesiology, Universitätsmedizin Greifswald

\section{Agnes Flöel}

Department of Neurology, Universitätsmedizin Greifswald

Henry W.S. Schroeder

Department of Neurosurgery, Universitätsmedizin Greifswald Jan-Uwe Müller

Department of Neurosurgery, Universitätsmedizin Greifswald

\section{Robert Fleischmann}

Department of Neurology, Universitätsmedizin Greifswald https://orcid.org/0000-0001-8159-2658 


\section{Method Article}

\section{Keywords:}

Posted Date: November 30th, 2018

DOI: https://doi.org/10.21203/rs.2.36/v1

License: (c) (1) This work is licensed under a Creative Commons Attribution 4.0 International License. Read Full License

Version of Record: A version of this preprint was published at JMIR Research Protocols on February 13th, 2020. See the published version at https://doi.org/10.2196/15488. 


\section{Abstract}

\section{Background}

Elderly people are a rapidly growing proportion of the world's population that increasingly undergo major elective spine surgery. They are yet at particular high risk for postoperative delirium (POD), which is associated with longer hospital stays, higher costs, risk for delayed complications, long-term care dependency and cognitive dysfunction (POCD). It is insufficiently understood, which mechanisms and, particularly modifiable, risk factors contribute to the development of POD and POCD following these major but plannable surgeries. A better understanding thereof would help to adapt medical management and surgical strategies to individual risk profiles.

Methods

This is a single-center observational study that is jointly conducted by the departments of Neurosurgery, Neurology and Anesthesiology at a tertiary care hospital in Germany. All patients presenting to the neurosurgery outpatient clinic or ward for elective spine surgery are screened for eligibility. Inclusion criteria are age $\geq 60$ years, indication for elective spine surgery, ability to give informed consent without assistance and speaking German natively. Exclusion criteria include presence of neurodegenerative disease, diagnosis of any psychiatric disease, medication with central nervous system activity (e.g. antidepressants, antipsychotics, sedatives), impossibility to participate in follow-up, participation in an interventional trial, presence of electronic or displaceable metallic implants and active neoplasm. All patients are evaluated for their preoperative cognitive abilities and physical, mental and social health and wellbeing. They additionally receive preoperative cerebrovascular ultrasound and structural and functional brain imaging. The immediate postoperative period includes screening for POD and the investigation of markers of (neuro-)inflammation. Preoperative examinations are repeated three months postoperatively to investigate the presence of POCD and its mechanisms.

\section{Discussion}

This is the first study to prospectively evaluate risk factors for POD and POCD in spine surgery including comprehensive pre- and postoperative assessments of cognitive abilities, markers of (neuro-)inflammation, cerebral vasculature and structural and functional neuroimaging. The identification of, possibly common, mechanisms underlying POD and POCD would be a major step towards the definition of effective interventional strategies early in or even before the postoperative period, including the adaptation of surgical strategies to individual risk profiles.

\section{Background}


The world's older population continues to grow at an unprecedented rate. Recent scenarios expect the number of people aged 60 years and older to triple and their population's proportion to outreach $20 \%$ by the year 2050 (1). It is well established that these elderly people are at increased risk for an episode of delirium following major surgery (2). Delirium is an acute brain dysfunction defined by the Diagnostic and Statistical Manual of Mental Disorders (DSM-5) as a disturbance in attention and awareness that develops over a short period of time, fluctuates, and is accompanied by a change in cognition (3). These disturbances are not explained completely by an established neurological disorder or disease. Postoperative delirium (POD) typically evolves within 72 hours following surgery and may be continuous with delirium following cessation of anesthesia but typically develops several hours later $(4,5)$. It is associated with increased complications rates, nursing times per patient, length of hospital stay, per-day hospital costs and one-year health care costs (6-8). While the full pathophysiology of POD remains to be elucidated, current literature suggests an underlying multicausal model that includes neuroinflammation, brain network dysfunction, endocrine stress response and neurotransmitter imbalance (9-13). POD was long considered a reversible condition, but it is now established that affected patients do no return to their prior quality of life and employment (14-16). In line with this notion, elderly patients are additionally affected by postoperative cognitive dysfunction (POCD) that persists in about $30-50 \%$ of cases after resolution of POD or develops independently up to 3 months following surgery $(5,17,18)$. Albeit POCD can develop in the absence of POD, more severe POD increases the likelihood of POCD indicating that both entities share at least some of their underlying mechanisms $(19,20)$. Supporting the idea of shared mechanisms, POD and POCD were both shown to accelerate the rate of cognitive decline and to increase the risk of long-term mild cognitive impairment/dementia, which may ultimately lead to long-term care dependency and institutionalization (18, 20-24).

Despite this growing body of literature acknowledging unfavorable effects of major surgery on cognitive function, the incidence of spinal surgery is increasing, and progressively involves patients aged 60 years and older (25). This trend is exemplified in a disproportional 28 -fold increase in anterior cervical fusion procedures in elderly patients as compared to an overall 8-fold increase in surgery in the National Hospital Discharge Survey from 1990 to 2004 (26). Other procedures including lumbar fusion, laminectomy and discectomy exhibit an ongoing and similar progression $(27,28)$. Even though surgery may sometimes be unnecessary and stricter application of guidelines pose a viable means to decrease postoperative cognitive complications in some cases, surgery is often inevitable to preserve or restore patients' abilities to participate in activities of daily living $(27,29)$. Knowledge of, particularly modifiable, risk factors for POD and POCD is therefore imperative to enhance informed patient consent, adjust anesthetic and surgical strategies to individual risk profiles and facilitate appropriate postoperative monitoring (30). Numerous risk prediction models have been developed, yet recent studies highlight that a general application of these models in clinical routine is limited, not least because trajectories of cognitive decline are not independent of the type of surgery $(20,24,31,32)$. For example, patients who exhibited POCD following cardiac surgery improved cognitive function after one year compared to their baseline level, which contradicts results from mixed surgical populations $(24,32)$. Differences in preoperative cognitive function and mechanisms underlying cognitive dysfunction possibly resolve some 
of the discrepancy, which highlights that surgical type-specific studies are required to identify mechanisms of POD and POCD unique to these procedures and to validate findings from other, including mixed, cohorts $(5,20,31,33)$.

Five prospective studies evaluated POD following spine surgery and unambiguously identified advanced age, lower preoperative cognitive level, general anesthesia and intraoperative hypotension as risk factors (34-38). The reported incidence of delirium yet varied substantially between $8 \%$ and $41 \%$, which is not resolved by clear methodological differences since all studies included patients of similar age (mean age between 70 and 75 years) and used validated instruments for the diagnosis of delirium. A notable difference between studies is a proportional increase of durations of surgery and POD incidences, which was more distinctly elaborated in a subgroup analysis by Brown et al. $(30,37)$. In line with this notion, retrospective analyses indicated that less complex and shorter interventions such as simple decompressions were associated with lower POD and complication rates as compared to complex fusion and instrumentation procedures $(39,40)$.

We thus hypothesize that the duration of spine surgery is a predictor of POD incidence in spinal surgery, which was not previously tested as primary endpoint in a prospective and sufficiently powered study. Evidence in favor of our hypothesis would justify adaptation of surgical interventions to individual risk profiles as a viable means to reduce the incidence and sequelae of POD without withholding necessary surgery from affected elderly patients. Secondary endpoints include POD severity, POD duration and postoperative complications. This study will also evaluate the relationship between POD and POCD in spine surgery, which was not done before but declared one of the most relevant study areas in a recently published multinational and interprofessional delirium research agenda (41). Additional endpoints include long-term cognitive function, quality of life, activities of daily living, mood and frailty. Underlying pathophysiological mechanisms will be investigated through ultrasound of the cerebral vasculature, structural and resting-state functional magnetic resonance imaging (sMRI, rs-fMRI), markers of (neuro-)inflammation and metabolomics.

\section{Methods And Design}

\section{Setting and registration}

The cognitive dysfunction following elective spine surgery in elderly patients (CONFESS) study is a prospective single-center observational study that is jointly conducted by the Department of Neurosurgery and Neurology in cooperation with the Department of Anesthesiology at the University Hospital Greifswald, Germany, a 950-bed tertiary care hospital. The trial was approved by the Institutional Review Board of the University of Greifswald under the number BB 192/17 and registered at ClinicalTrials.gov under registration number NCT03486288. The Standard Protocol Items: Recommendations for Interventional Trials (SPIRIT) checklist is provided as supplemental material. 


\section{Patient recruitment and study design}

The study was initiated in February 2018 and is actively recruiting patients presenting to the Department of Neurosurgery for elective spine surgery. All patients seen in Neurosurgery outpatient clinics or inpatient wards are screened for eligibility. Patients can be enrolled if they are at least 60 years of age, scheduled for elective spine surgery without opening the dura, can give informed consent him-/herself and are German native speakers. Exclusion criteria comprise any diagnosis of dementia or neurodegenerative disease, psychiatric disease, prescription of CNS-active medication (e.g. antidepressants, antipsychotics, sedatives, alpha-1-receptor antagonists), impossibility to participate in follow-up, participation in an interventional trial, electronic or displaceable metallic implants or active neoplasms. Informed consent to participate can only be given the patient him-/herself. All baseline examinations are scheduled within 14 days prior to surgery (V0). The day of surgery (V1) includes documentation of routine procedures and a close follow-up of patients in the post-anesthesia care unit (PACU) for at least 2 hours, or longer depending on the clinical situation. Patients are afterwards routinely transferred to the neurosurgical ward or may occasionally require intermediate/intensive care treatment. Postoperative visits (V2) continue for at least 72 hours postoperatively and include detailed documentation of primary and secondary endpoints. If patients develop POD within 72 hours, daily follow-ups continue until no signs of POD are documented over a period of 24 hours or the patient is discharged, e.g. for rehabilitation. Patients are routinely seen in the neurosurgical outpatient clinic 3 months postoperatively and in this context receive additional follow-up examinations (V3). Patients who agreed to be contacted via telephone finally undergo a telephone assessment of their cognitive and functional status one year following surgery (V4). A synopsis of the visit plan is provided in figure 1. Recruitment is planned to be completed by December 2019. The last in-hospital follow-up visit is accordingly scheduled for March 2020, the last telephone interview is anticipated for December 2020.

\section{Routine surgical procedures}

Patients included in this study suffer from degenerative spinal diseases. This included cervical disc herniation and stenosis, thoracical and lumbar stenosis and degenerative instability. All patients are enrolled in elective spinal surgical procedures without an anticipated dural opening and with a minimum scheduled operative time of 60 minutes. All procedures are performed by standard neurosurgical guidelines. The operation is always carried out by an experienced spine surgeon. The patients are optimally positioned on the operating table. All patient are operated in prone position, without compression of the abdomen by using proper positioning cushions. Each patient receives a thermal blanket throughout the operation. All operations are performed with the help of an operating microscope and a mobile X-ray device (C-arm). Typical procedures will 
include anterior cervical discectomy and fusion (acdf), posterior cervical decompression and fusion, multisegmental thoracical and lumbar decompression as well as standard and complex multilevel spinal fusion.

\section{Routine anesthetic procedures}

The preoperative period before the induction of anesthesia is in accordance with international standards for elective interventions. Food is withheld for a minimum of six hours and water for two hours before anesthesia starts. Oral premedication is performed with midazolam $(0.1 \mathrm{mg} * \mathrm{~kg}-1)$ depending on individual levels of preoperative excitement. After placement of a peripheral intravenous line (18 or 20gauge catheter), anesthesia is induced by intravenous injection of sufentanyl (0.3-0.6 mg*kg-1) and propofol (1.5-2.5 mg*kg-1). Muscular relaxation is performed by intravenous injection of cisatracurium $\left(1.5 \mathrm{mg}^{\star} \mathrm{kg}-1\right)$. Anesthesia is maintained by a balanced anesthesia with sevoflurane. The target alveolar concentration chosen was 0.8-1.0 x MAC. Adequate anesthetic depth was verified via continuous monitoring of the bispectral index (BIS) and real-time electroencephalography (EEG) waveforms along the scalp. Estimated insensitive fluid losses were replaced isovolemic by intravenous infusion of blood isotonic electrolyte solution without lactate. A convective air warming system is used to keep the body temperature constant and normothermic. Patients are endotracheally intubated and mechanically ventilated (PCV, FiO2 $0.4-0.6)$ at a rate of $10-18$ per minute and a positive end-expiratory pressure of 5-10 $\mathrm{cm} \mathrm{H2O}$. Tidal volume is adjusted individually on the basis of the end tidal carbon dioxide (EtCO2, capnography) monitoring or of a blood gas analysis and the measured $\mathrm{PaCO} 2$.

All patients are routinely placed in supine position. Continuous recording of vital parameters includes five lead electrocardiography, pulse oximetry (SpO2) and noninvasive blood pressure measurement (NIBP). Individual patients receive an arterial catheter placed in the radial artery depending on their preoperative risk profile to enable close monitoring of hemodynamics and arterial blood gas. Hypotensive situations are managed through fluid challenges and continuous medication with norepinephrine. Recovery from anesthesia was monitored in the PACU.

\section{Primary outcome measure}

This study's primary endpoint is that the duration of surgery is a predictor of POD incidence. POD is expected to develop within 72 hours following surgery and screening is performed every eight hours within this period in every patient using the validated Nursing Delirium Screening Scale (Nu-DESC) $(5,42)$. A recent review of established delirium screening tools found psychometric properties to be best for the Nu-DESC and Confusion Assessment Method (CAM) and both tools are recommended to be used by the European Society of Anaesthesiology guideline on $\operatorname{POD}(43,44)$. This study uses the Nu-DESC since the CAM was recently shown to be difficult to implement in practice, the Nu-DESC can be applied in less than two minutes and it is suitable for screening by trained nurses (44-46). Morning and day shift screenings 
are performed by trained physicians during workdays, other screenings are done by trained nurses. Interrater reliability is not a concern using the Nu-DESC since it was reported to be substantial to excellent (44). Sensitivity of the Nu-DESC was reported between $32 \%-96 \%$ (82\% in its German version) and specificity found to be up to $87 \%$ using a cut-off of $\geq 2$, which is among the best detection rates that can be expected $(43,44,47)$. In this study, positive screening results require confirmation by Diagnostic and Statistical Manual of Mental Disorders, Fifth Edition (DSM-5), criteria applied by a trained physician to further increase diagnostic specificity (3).

\section{Secondary outcome measures}

POD assessments extending on primary outcome measures are performed throughout V1 and V2 and include POD incidence over the whole in-hospital period, incidence of subsyndromal delirium, POD severity and duration. Severity is evaluated using the CAM severity (CAM-S) scale (48). Subsyndromal delirium includes Nu-DESC ratings greater than zero that do not fulfil criteria for delirium. Chart-based POD screening is used to complement POD screening beyond the Nu-DESC screening period to estimate the overall in-hospital POD incidence. Chart-based methods can furthermore increase the overall sensitivity when combined with interview methods in the first 72 hours, yet their sensitivity tends to be lower in the absence of psychomotor agitation or inappropriate behaviour when used stand-alone (49).

Preoperative and postoperative cognitive abilities are evaluated at V0 and V3 using the Consortium to Establish a Registry for Alzheimer's Disease Plus test battery (CERAD-Plus) and multiple-choice word test type B (MWT-B) $(50,51)$. The CERAD-Plus includes assessments of orientation, visual naming, phonematic speed, semantic fluency, verbal episodic memory (encoding, error control, recall, discriminability), non-verbal episodic memory (encoding, recall), visuoconstruction abilities, attention, executive speed and functions. MWT-B results reflect the general intellectual level.

Systemic inflammation, neuroinflammation and neuronal injury are assessed with blood samples taken at V0, V1 (immediately after surgery in the PACU) and the first two days of V2, i.e. the first and second postoperative day. Systemic inflammation is characterized by white blood cell count, C-reactive protein (CRP), interleukins and tumor-necrosis factor alpha (TNFa) among others that are considered to contribute to the pathogenesis of delirium $(13,52-54)$. Markers of neuroinflammation and neuronal injury include glial fibrillary acidic protein (GFAP), neuron specific enolase (NSE) and neurofilament levels (5557). Neopterin and malondialdehyde levels are established surrogate markers of oxidative (neuronal) stress $(58,59)$. Given the increasingly recognized role of genetic predisposition for neuronal plasticity, preoperative analysis of brain-derived neurotropic factor (BDNF) polymorphism is intended (60).

Patient-reported quality of life is assessed at V0 and V3 through the Short Form (36) Health Survey (SF36) and Patient Records and Outcome Management Information System 29-item profile (PROMIS-29) (61, 62). Patients' relatives are furthermore handed a proxy version of the PROMIS-29 to evaluate agreements of self- and proxy-reported quality of life regarding individual domains (PROMIS-29 proxy). Proxy reports 
are a valuable tool to assess patient outcome when cognitive impairment impedes self-report, yet no study previously evaluated if changes of quality of life following surgery are similarly rated by patients and their proxies (63). Additional patient-related outcome measures include preoperative levels and postoperative changes of frailty as assessed by the Groningen frailty indicator, neck or low back pain related disability using the Oswestry Disability Index and anxiety and depression as rated by the Hospital Anxiety and Depression Scale (64-66).

Structural and resting-state functional magnetic resonance imaging (rs-fMRI) have become methods of choice to investigate neuronal correlates of pathology related cognitive decline in delirium (67). While there is a promising prospect for EEG biomarkers to facilitate decision-making in clinical situations and to investigate neurophysiological changes during an episode of delirium, the spatial resolution of MRI enables the detailed investigation of brain structures and network interactions associated with the risk for POD and - possibly preventable - mechanisms leading to POCD and long-term cognitive impairment (11, 68). A recent review found that most research in the field was done in cardiovascular surgery or ICU patients limiting the generalizability of previous findings (67). Moreover, only two patient cohorts were prospectively evaluated for MRI changes following an episode of delirium and none of the studies had a focus on POD or $\operatorname{POCD}(11,69,70)$. This is therefore the first study to perform longitudinal assessments of sMRI and rs-MRI measures of brain structure and function in a well-defined surgical population.

A recent retrospective analysis found that hemodynamic stenoses of the cerebral vasculature may predict the incidence of POD in spine surgery (71). This study includes a prospective evaluation of this hypothesis and additionally includes an evaluation of arterial pulsatility that was suggested as an amply available biomarker of cognitive reserve capacity (72).

\section{Sample size calculation and statistical methods}

The primary hypothesis of this study is that the duration of surgery is a continuous predictor for POD in a binary logistic regression model, which was not previously tested as primary endpoint in a prospective study. Five studies performed preliminary evaluations of this relationship treating duration of surgery as categorical variable and secondary endpoint. They reported mean delirium incidences of $14 \%$ for durations of surgery less than 180 minutes, $33 \%$ for 180 to 300 minutes and $48 \%$ for surgeries lasting longer than 300 minutes (34-38). We extend on these previous findings by using a binary logistic regression model that provides the intriguing perspective to estimate how the odds of becoming delirious change with every minute of surgery. We used a well-established simulation based approach to estimate an adequate sample size to test our hypothesis (73). The simulation utilized a representative population of surgical patients that was based on information from the clinical information system, which included duration, type and frequency of spine surgeries performed by the Department of Neurosurgery in 2016. Samples were randomly drawn from this population and included in repeated study simulations while iteratively increasing sample sizes. This process continued until $80 \%$ of simulations run for a given sample size yielded significant regression coefficients in a two-tailed Wald-test at a $5 \%$ alpha level. This 
approach yielded that 182 patients need to be tested so that the power to reject the null hypothesis is $80 \%$. Anticipating a drop-out rate of $10 \%, 200$ patients are planned to be enrolled in this study.

Secondary endpoints will be analyzed using appropriate summary measures depending on the distribution of data. Categorical data will be presented as absolute and relative frequencies. Continuous data will be presented as mean or median values with $95 \%$ confidence intervals. Statistical analysis will be performed using STATA version 15.1 (StataCorp, College Station, Texas, USA) and MATLAB 2018a (MathWorks, Natick, Massachusetts, USA).

MRI analysis will include quantification of brain atrophy through estimations of pre- versus postoperative changes of tissue volumes. To assess the impact of cortical atrophy, brain grey matter volume is going to be included as an additional covariate in statistical analyses (74). Preoperative extent and postoperative changes of white matter lesions are going to be quantified using the age-related white matter changes score (75). Resting-state analyses will be conducted as previously published and particularly include the default-mode (DMN), task-positive network (TPN), salience and dorsal attention network $(11,76,77)$. Regression analyses will be used to correlate network changes with alterations in domains of cognitive dysfunction.

\section{Discussion}

This is the first study to prospectively evaluate risk factors for POD and POCD in spine surgery including comprehensive pre- and postoperative assessments of cognitive function, markers of systemic and neuroinflammation, metabolomics, cerebral vasculature and structural and functional neuroimaging. There are no other ongoing registered studies with a similar focus (78). Few prospective studies evaluated risk factors and mechanisms of POD in the context of spine surgery and were already discussed above, however neither of the studies assessed associations of POD and POCD, which is required to disentangle pathways that promote either one or both postoperative cognitive disorders. Available retrospective studies do not resolve this issue given diagnostic inaccuracies $(39,49)$. Yet, identification of, possibly common, mechanisms underlying POD and POCD would be a major step towards the definition of effective interventional strategies early in or even before the postoperative period, including the adaptation of surgical strategies to individual risk profiles (41). Despite this exciting prospect for the application of possible findings from this study, there are important methodological and conceptual issues that require close attention concerning data acquisition, analysis and interpretation.

\section{Diagnostic challenges to identify delirium}

Accurate diagnosis of POD is a major concern in all studies in the field. While diagnosing the patient using DSM-5 criteria applied by a trained specialist (e.g. psychiatrist, neurologist, intensivist) is considered the method of choice, this approach is impractical in clinical routine and even challenging in study environments given the high prevalence of delirium and its fluctuating character that requires 
multiple assessments per day $(3,79,80)$. The use of screening tools, which are time-efficient and can be applied by trained nurses or physicians, is hence an important step towards a timely diagnosis and effective treatment of delirious patients $(30,43)$. In order to achieve a balanced trade-off between feasibility and accuracy of diagnostic tools, we chose a combination of methods for the detection of POD regarding our primary endpoint. Screening for POD is performed using the Nu-DESC with a cutoff of two points, which provides a sensitivity and specificity of about $80 \%$ (44). Lack of specificity is counterbalanced by subsequent confirmation of positive screening results by DSM- 5 criteria (3). While this strict approach may miss subsyndromal and mild cases of POD, we argue that it will provide robust results that are not susceptible for confounding variance introduced by cases of marginal delirium. In this context, it is important to note that current diagnostic criteria are based on phenotypes and do not reflect neurobiological endotypes, which inevitably includes the possibility that none of the available diagnostic methods will sufficiently discriminate POD endotypes from variants of physiological brain states or altered brain states of other causes $(41,81,82)$. Given this uncertainty, we will run secondary analyses on subsyndromal cases of POD based on Nu-DESC screening and chart-review and evaluate if associated pathophysiological changes are continuous with endotypes of full POD.

\section{Contribution of anesthesia to neuronal injury}

Anesthesia is considered one of the major contributors to the development of POD and POCD and therefore requires close attention in every study in the field $(4,83)$. It is well established that the cumulative dose of anesthetics applied during surgery and the depth of sedation are modifiable risk factors for perioperative brain injury (84). This study therefore includes continuous BIS monitoring for depth of anesthesia, which allows to retrospectively adjust the statistical model for confounding variance (85). Possible mechanisms underlying nocuous effects of anesthetics include disruption of neuronal oscillations, importantly those associated with amyloid cleavage, (86), induction of tau hyperphosphorylation (87), initiation of apoptotic cell-death pathways via caspase activation (88) and disruption of cholinergic transmission regulating microglia activity $(89,90)$. While these mechanisms were identified using single anesthetics, there is no proven benefit from using one drug over another, e.g. sevoflurane or propofol, on the incidence of $\operatorname{POD}(91,92)$. In context of this preliminary evidence, we chose to standardize the anesthetic procedure using the same drugs in all patients unless the regimen needs to be changed for medical reasons, e.g. due to allergies or contraindications.

\section{Role of inflammatory pathways}

Investigating the role of mediators of systemic and neuroinflammation has become one of the cornerstones of POD and POCD research (41). Animal models brought about exciting results including upregulation of several inflammatory pathways and decreased neuronal plasticity in hippocampal regions while cortical regions were generally spared, which is in line with cognitive deficits observed in humans $(12,13,33,93,94)$. This motivated studies in humans that assessed the association of markers 
of inflammation with POD and POCD, yet findings were ambiguous. While some studies reported that systemic levels of interleukins, particularly interleukin-6, and C-reactive protein were predictors of brain injury, delirium and subsequent cognitive impairment $(53,54,95)$, others do not find similar associations $(53,96,97)$. Possible reasons for this discrepancy are that some studies included cases of ICU-delirium, that concentrations of markers of inflammation vary substantially between types of surgery $(33,98)$ and that neuroinflammatory effects seem to depend on the extent of preexisting neurodegeneration, which was rarely controlled for $(12,99)$. Another unresolved issue is how systemic and neuroinflammation interact to cause brain injury (90). Several possible mechanisms were studied in animal models and include passive diffusion through leaky blood brain barrier (100), carrier-mediated transport (101) and de novo central production mediated through vagal afferents $(102,103)$. While opening of the blood barrier induced by anesthesia is an intriguing and prevailing explanation, cerebrospinal fluid (CSF) levels and serum concentration of marker of inflammation are not correlated suggesting the additional involvement of other mechanisms that remain to be elucidated $(56,104)$.

\section{Structural and functional imaging}

Studying the pathophysiology of POD and POCD using MRI provides numerous opportunities to asses brain structure and function. Previous studies investigating SMRI changes found that preoperative white matter hyperintensities $(\mathrm{WMH})$ were predictors of $\operatorname{POD}(70,105,106)$. These studies, however, evaluated patients undergoing cardiac surgery or treated in ICU, which limits their generalizability. As outlined above, cognitive trajectories in cardiac surgery can be expected to differ from other conditions given their unique hemodynamic situation that possibly affects cerebrovascular autoregulation (5). Development of ICU delirium is associated with several risk factors that are rarely present in patients following spine surgery such as continuous sedation, ventilation, noisy environment, sleep deprivation, compromised hemodynamics and repeated painful invasive procedures, all of which limit the interpretation of WMH as independent risk factor $(18,107)$. In support of this limitation, Cavallari et al. examined WMH as a risk factor in a surgical population that mainly comprised orthopedic patients not treated in ICU and found no significant association with delirium (108). A recent review concluded that prospective studies are needed to resolve current uncertainties regarding the significance of, particularly vascular, structural abnormalities in SMRI (109). The situation is similar concerning the role of preexisting cortical atrophy on the risk to develop POD. Some studies reported generalized or focal (temporal lobe, limbic system) grey matter atrophy to increase the risk for delirium while others did not find this association $(69,110)$. A recent review interpreted differences in structural imaging to be mainly due to the focus on cardiac surgery and ICU patients that are difficult to generalize (67). Our study provides several potential benefits regarding mentioned limitations. We focus on a population that is less confounded by critical illness and also include pre- and postoperative imaging to overcome variance in the general population that limits cross-sectional comparisons to controls. We expect that these benefits and concomitant evaluations of cognitive and inflammatory profiles will help elucidate the role of structural MRI changes for POD and POCD. 
There are no studies that performed fMRI before surgery in order to identify brain network properties that predispose for the development of POD and POCD (67). This is surprising given the broad acceptance of models that consider cognitive resilience a relevant protective mechanism and that $\mathrm{fMRI}$ is the method of choice to investigate neurobiological substrates underlying resilience (111-113). This study aims to fill this gap by correlating functional data with perioperative cognitive profiles. The combination of pre- and postoperative rs-fMRI will furthermore help to disentangle brain networks that are affected by the surgical procedure and lead to sequel cognitive deficits (81). There are currently only few studies that provide cross-sectional data and allow for a hypothesis of involved networks. These include a loss of anticorrelation between the TPN and DMN, decreased DMN functional connectivity, reduced functional network integration and efficiency, and decreased functional connectivity between the posterior cingulate and superior frontal gyrus $(11,114-116)$.

\section{Investigation of perioperative cognitive function}

The association between POD and POCD is an ongoing matter of debate (20). While POD may accelerate the trajectory of cognitive decline, it is also possible that POD is a marker of a rapid cognitive decline but not accelerating it or that both conditions are unrelated (117). Recent consensus statements suggest that studies in the field should include investigations of both POD and POCD to elucidate their relationship and disentangle shared mechanisms $(41,43)$. Cognitive testing should comprise pre- and postoperative assessments to account for baseline differences, examine a broad spectrum of cognitive domains and account for ceiling effects in good performers and floor effects in bad performers $(118,119)$. This study uses the MWT-B that allows to adjust for baseline intelligence. The CERAD-Plus test battery enables repeated measurements of cognitive abilities in multiple domains and normative age-, education-, and gender-specific databases are available (50).

\section{Trial status}

Recruitment started in April 2018 and the study is currently recruiting patients. Data collection is expected to be finished by December 2020.

\section{Declarations}

\section{Ethics approval and consent to participate}

The study was approved by the Institutional Review Board of the Universitätsmedizin Greifswald (BB 192/17).

\section{Consent for publication}


Not applicable.

\section{Availability of data and material}

The datasets used and/or analysed during the current study are available from the corresponding author on reasonable request.

\section{Competing interests}

The authors declare that they have no competing interests.

\section{Funding}

This study does not receive any third-party funding.

\section{Authors contributions}

JM, SN, MD, AV, SR, TU, AF, JUM and RF designed the study and wrote the initial protocol. BvS, ER, SS, HK, $\mathrm{KH}$ and HWSS provided advice and input into the protocol. All authors read and approved the final manuscript.

\section{Acknowledgements}

Not applicable.

\section{References}

1. U.S. Census Bureau. An Aging World: 2015. International Population Reports [Internet]. 2016 18.06.2017]. Available from: https://www.census.gov/content/dam/Census/library/publications/2016/demo/p95-16-1.pdf.

2. Fong TG, Tulebaev SR, Inouye SK. Delirium in elderly adults: diagnosis, prevention and treatment. Nature reviews Neurology. 2009;5(4):210-20.

3. American Psychiatric Association. Diagnostic and statistical manual of mental disorders, (DSM-5®): American Psychiatric Pub; 2013. 
4. Card E, Pandharipande P, Tomes C, Lee C, Wood J, Nelson D, et al. Emergence from general anaesthesia and evolution of delirium signs in the post-anaesthesia care unit. British journal of anaesthesia. 2015;115(3):411-7.

5. Berger M, Terrando N, Smith SK, Browndyke JN, Newman MF, Mathew JP. Neurocognitive Function after Cardiac Surgery: From Phenotypes to Mechanisms. Anesthesiology. 2018.

6. Siddiqi N, House AO, Holmes JD. Occurrence and outcome of delirium in medical in-patients: a systematic literature review. Age and ageing. 2006;35(4):350-64.

7. Inouye SK, Schlesinger MJ, Lydon TJ. Delirium: a symptom of how hospital care is failing older persons and a window to improve quality of hospital care. The American journal of medicine. 1999;106(5):565-73.

8. Leslie DL, Inouye SK. The importance of delirium: economic and societal costs. Journal of the American Geriatrics Society. 2011;59 Suppl 2:S241-3.

9. Maclullich AM, Ferguson KJ, Miller T, de Rooij SE, Cunningham C. Unravelling the pathophysiology of delirium: a focus on the role of aberrant stress responses. Journal of psychosomatic research. 2008;65(3):229-38.

10. Watne LO, Idland AV, Fekkes D, Raeder J, Frihagen F, Ranhoff AH, et al. Increased CSF levels of aromatic amino acids in hip fracture patients with delirium suggests higher monoaminergic activity. BMC Geriatr. 2016;16:149.

11. van Montfort SJT, van Dellen E, van den Bosch AMR, Otte WM, Schutte MJL, Choi SH, et al. Restingstate fMRI reveals network disintegration during delirium. Neurolmage Clinical. 2018;20:35-41.

12. Hennessy E, Gormley S, Lopez-Rodriguez AB, Murray C, Murray C, Cunningham C. Systemic TNF-alpha produces acute cognitive dysfunction and exaggerated sickness behavior when superimposed upon progressive neurodegeneration. Brain, behavior, and immunity. 2017;59:233-44.

13. Terrando N, Monaco C, Ma D, Foxwell BM, Feldmann M, Maze M. Tumor necrosis factor-alpha triggers a cytokine cascade yielding postoperative cognitive decline. Proceedings of the National Academy of Sciences of the United States of America. 2010;107(47):20518-22.

14. Pandharipande PP, Girard TD, Jackson JC, Morandi A, Thompson JL, Pun BT, et al. Long-term cognitive impairment after critical illness. The New England journal of medicine. 2013;369(14):1306-16.

15. Norman BC, Jackson JC, Graves JA, Girard TD, Pandharipande PP, Brummel NE, et al. Employment Outcomes After Critical Illness: An Analysis of the Bringing to Light the Risk Factors and Incidence of Neuropsychological Dysfunction in ICU Survivors Cohort. Critical care medicine. 2016;44(11):2003-9.

16. Jackson JC, Pandharipande PP, Girard TD, Brummel NE, Thompson JL, Hughes CG, et al. Depression, post-traumatic stress disorder, and functional disability in survivors of critical illness in the BRAIN-ICU 
study: a longitudinal cohort study. Lancet Respir Med. 2014;2(5):369-79.

17. Rudolph JL, Marcantonio ER, Culley DJ, Silverstein JH, Rasmussen LS, Crosby GJ, et al. Delirium is associated with early postoperative cognitive dysfunction. Anaesthesia. 2008;63(9):941-7.

18. Sakusic A, O'Horo JC, Dziadzko M, Volha D, Ali R, Singh TD, et al. Potentially Modifiable Risk Factors for Long-Term Cognitive Impairment After Critical Illness: A Systematic Review. Mayo Clin Proc. 2018;93(1):68-82.

19. Vasunilashorn SM, Fong TG, Albuquerque A, Marcantonio ER, Schmitt EM, Tommet D, et al. Delirium Severity Post-Surgery and its Relationship with Long-Term Cognitive Decline in a Cohort of Patients without Dementia. J Alzheimers Dis. 2018;61(1):347-58.

20. Devinney MJ, Mathew JP, Berger M. Postoperative Delirium and Postoperative Cognitive Dysfunction: Two Sides of the Same Coin? Anesthesiology. 2018.

21. Inouye SK, Bogardus ST, Jr., Charpentier PA, Leo-Summers L, Acampora D, Holford TR, et al. A multicomponent intervention to prevent delirium in hospitalized older patients. The New England journal of medicine. 1999;340(9):669-76.

22. Saczynski JS, Marcantonio ER, Quach L, Fong TG, Gross A, Inouye SK, et al. Cognitive trajectories after postoperative delirium. The New England journal of medicine. 2012;367(1):30-9.

23. Inouye SK, Marcantonio ER, Kosar CM, Tommet D, Schmitt EM, Travison TG, et al. The short-term and long-term relationship between delirium and cognitive trajectory in older surgical patients. Alzheimers Dement. 2016;12(7):766-75.

24. Sprung J, Roberts RO, Weingarten TN, Nunes Cavalcante A, Knopman DS, Petersen RC, et al. Postoperative delirium in elderly patients is associated with subsequent cognitive impairment. British journal of anaesthesia. 2017;119(2):316-23.

25. Deyo RA, Mirza SK, Martin BI, Kreuter W, Goodman DC, Jarvik JG. Trends, major medical complications, and charges associated with surgery for lumbar spinal stenosis in older adults. Jama. 2010;303(13):1259-65.

26. Marawar S, Girardi FP, Sama AA, Ma Y, Gaber-Baylis LK, Besculides MC, et al. National trends in anterior cervical fusion procedures. Spine (Phila Pa 1976). 2010;35(15):1454-9.

27. Epstein NE. Spine surgery in geriatric patients: Sometimes unnecessary, too much, or too little. Surgical neurology international. 2011;2:188.

28. Statistisches Bundesamt. Operationen und Prozeduren der vollstationären Patientinnen und Patienten in Krankenhäusern. Fallpauschalenbezogene Krankenhausstatistik (DRG-Statistik). Wiesbaden:

Statisches Bundesamt; 2015. 
29. Epstein NE, Hood DC. "Unnecessary" spinal surgery: A prospective 1-year study of one surgeon's experience. Surgical neurology international. 2011;2:83.

30. Nazemi AK, Gowd AK, Carmouche JJ, Kates SL, Albert TJ, Behrend CJ. Prevention and Management of Postoperative Delirium in Elderly Patients Following Elective Spinal Surgery. Clinical spine surgery. 2017;30(3):112-9.

31. Lee A, Mu JL, Joynt GM, Chiu CH, Lai VKW, Gin T, et al. Risk prediction models for delirium in the intensive care unit after cardiac surgery: a systematic review and independent external validation. British journal of anaesthesia. 2017;118(3):391-9.

32. Sauer AC, Veldhuijzen DS, Ottens TH, Slooter AJC, Kalkman CJ, van Dijk D. Association between delirium and cognitive change after cardiac surgery. British journal of anaesthesia. 2017;119(2):308-15.

33. Hovens IB, van Leeuwen BL, Mariani MA, Kraneveld AD, Schoemaker RG. Postoperative cognitive dysfunction and neuroinflammation; Cardiac surgery and abdominal surgery are not the same. Brain, behavior, and immunity. 2016;54:178-93.

34. Seo JS, Park SW, Lee YS, Chung C, Kim YB. Risk factors for delirium after spine surgery in elderly patients. Journal of Korean Neurosurgical Society. 2014;56(1):28-33.

35. Lee YS, Kim YB, Lee SH, Park YS, Park SW. The Prevalence of Undiagnosed Presurgical Cognitive Impairment and Its Postsurgical Clinical Impact in Older Patients Undergoing Lumbar Spine Surgery. Journal of Korean Neurosurgical Society. 2016;59(3):287-91.

36. Soh S, Shim JK, Song JW, Kim KN, Noh HY, Kwak YL. Postoperative Delirium in Elderly Patients Undergoing Major Spinal Surgery: Role of Cerebral Oximetry. Journal of neurosurgical anesthesiology. 2016.

37. Brown CHt, LaFlam A, Max L, Wyrobek J, Neufeld KJ, Kebaish KM, et al. Delirium After Spine Surgery in Older Adults: Incidence, Risk Factors, and Outcomes. Journal of the American Geriatrics Society. 2016;64(10):2101-8.

38. Li YN, Zhang Q, Yin CP, Guo YY, Huo SP, Wang L, et al. Effects of nimodipine on postoperative delirium in elderly under general anesthesia: A prospective, randomized, controlled clinical trial. Medicine. 2017;96(19):e6849.

39. Fineberg SJ, Nandyala SV, Marquez-Lara A, Oglesby M, Patel AA, Singh K. Incidence and risk factors for postoperative delirium after lumbar spine surgery. Spine (Phila Pa 1976). 2013;38(20):1790-6.

40. Saleh A, Thirukumaran C, Mesfin A, Molinari RW. Complications and readmission after lumbar spine surgery in elderly patients: an analysis of 2,320 patients. Spine J. 2017;17(8):1106-12. 
41. Pandharipande PP, Ely EW, Arora RC, Balas MC, Boustani MA, La Calle GH, et al. The intensive care delirium research agenda: a multinational, interprofessional perspective. Intensive care medicine. 2017;43(9):1329-39.

42. Lutz A, Radtke FM, Franck M, Seeling M, Gaudreau JD, Kleinwachter R, et al. [The Nursing Delirium Screening Scale (NU-DESC)]. Anasthesiol Intensivmed Notfallmed Schmerzther. 2008;43(2):98-102.

43. Aldecoa C, Bettelli G, Bilotta F, Sanders RD, Audisio R, Borozdina A, et al. European Society of Anaesthesiology evidence-based and consensus-based guideline on postoperative delirium. European journal of anaesthesiology. 2017;34(4):192-214.

44. van Velthuijsen EL, Zwakhalen SM, Warnier RM, Mulder WJ, Verhey FR, Kempen GI. Psychometric properties and feasibility of instruments for the detection of delirium in older hospitalized patients: a systematic review. International journal of geriatric psychiatry. 2016;31(9):974-89.

45. Gaudreau JD, Gagnon P, Harel F, Tremblay A, Roy MA. Fast, systematic, and continuous delirium assessment in hospitalized patients: the nursing delirium screening scale. J Pain Symptom Manage. 2005;29(4):368-75.

46. Wong EK, Lee JY, Surendran AS, Nair K, Della Maestra N, Migliarini M, et al. Nursing perspectives on the confusion assessment method: a qualitative focus group study. Age and ageing. 2018.

47. Luetz A, Balzer F, Radtke FM, Jones C, Citerio G, Walder B, et al. Delirium, sedation and analgesia in the intensive care unit: a multinational, two-part survey among intensivists. PloS one. 2014;9(11):e110935.

48. Inouye SK, Kosar CM, Tommet D, Schmitt EM, Puelle MR, Saczynski JS, et al. The CAM-S: development and validation of a new scoring system for delirium severity in 2 cohorts. Annals of internal medicine. 2014;160(8):526-33.

49. Saczynski JS, Kosar CM, Xu G, Puelle MR, Schmitt E, Jones RN, et al. A tale of two methods: chart and interview methods for identifying delirium. Journal of the American Geriatrics Society. 2014;62(3):518-24.

50. Stein J, Luppa M, Luck T, Maier W, Wagner M, Daerr M, et al. The assessment of changes in cognitive functioning: age-, education-, and gender-specific reliable change indices for older adults tested on the CERAD-NP battery: results of the German Study on Ageing, Cognition, and Dementia in Primary Care Patients (AgeCoDe). The American journal of geriatric psychiatry : official journal of the American Association for Geriatric Psychiatry. 2012;20(1):84-97.

51. Wiessner B, Felber W. [Agreement between 2 diagnostic intelligence test procedures (HAWIE and MWTB) in a sample of patients with pronounced psychopathology]. Psychiatr Neurol Med Psychol (Leipz). 1981;33(12):744-8. 
52. Androsova G, Krause R, Winterer G, Schneider R. Biomarkers of postoperative delirium and cognitive dysfunction. Front Aging Neurosci. 2015;7:112.

53. Liu X, Yu Y, Zhu S. Inflammatory markers in postoperative delirium (POD) and cognitive dysfunction (POCD): A meta-analysis of observational studies. PloS one. 2018;13(4):e0195659.

54. Vasunilashorn SM, Ngo LH, Chan NY, Zhou W, Dillon ST, Otu HH, et al. Development of a Dynamic Multi-Protein Signature of Postoperative Delirium. The journals of gerontology Series A, Biological sciences and medical sciences. 2018.

55. Caplan GA, Kvelde T, Lai C, Yap SL, Lin C, Hill MA. Cerebrospinal fluid in long-lasting delirium compared with Alzheimer's dementia. The journals of gerontology Series A, Biological sciences and medical sciences. 2010;65(10):1130-6.

56. Cape E, Hall RJ, van Munster BC, de Vries A, Howie SE, Pearson A, et al. Cerebrospinal fluid markers of neuroinflammation in delirium: a role for interleukin-1 beta in delirium after hip fracture. Journal of psychosomatic research. 2014;77(3):219-25.

57. Inoue R, Sumitani M, Ogata T, Chikuda H, Matsubara T, Kato S, et al. Direct evidence of central nervous system axonal damage in patients with postoperative delirium: A preliminary study of pNF-H as a promising serum biomarker. Neuroscience letters. 2017;653:39-44.

58. Hall RJ, Watne LO, Idland AV, Raeder J, Frihagen F, MacLullich AM, et al. Cerebrospinal fluid levels of neopterin are elevated in delirium after hip fracture. J Neuroinflammation. 2016;13(1):170.

59. Lopez MG, Pandharipande P, Morse J, Shotwell MS, Milne GL, Pretorius M, et al. Intraoperative cerebral oxygenation, oxidative injury, and delirium following cardiac surgery. Free Radic Biol Med. 2017;103:192-8.

60. Antal A, Chaieb L, Moliadze V, Monte-Silva K, Poreisz C, Thirugnanasambandam N, et al. Brain-derived neurotrophic factor (BDNF) gene polymorphisms shape cortical plasticity in humans. Brain Stimul. 2010;3(4):230-7.

61. Parker SG, Peet SM, Jagger C, Farhan M, Castleden CM. Measuring health status in older patients. The SF-36 in practice. Age and ageing. 1998;27(1):13-8.

62. Cella D, Yount S, Rothrock N, Gershon R, Cook K, Reeve B, et al. The Patient-Reported Outcomes Measurement Information System (PROMIS): progress of an NIH Roadmap cooperative group during its first two years. Med Care. 2007;45(5 Suppl 1):S3-S11.

63. Savel RH, Shiloh AL, Eisen LA. Tackling the tough questions: what was this patient like before they were critically ill? Critical care medicine. 2013;41(1):327-8. 
64. Steverink N. Measuring frailty: developing and testing the GFI (Groningen Frailty Indicator). The Gerontologist. 2001;41:236.

65. Fairbank JC, Couper J, Davies JB, O'Brien JP. The Oswestry low back pain disability questionnaire. Physiotherapy. 1980;66(8):271-3.

66. Zigmond AS, Snaith RP. The hospital anxiety and depression scale. Acta Psychiatr Scand. 1983;67(6):361-70.

67. Nitchingham A, Kumar V, Shenkin S, Ferguson KJ, Caplan GA. A systematic review of neuroimaging in delirium: predictors, correlates and consequences. International journal of geriatric psychiatry. 2017.

68. Fleischmann R, Trankner S, Bathe-Peters R, Ronnefarth M, Schmidt S, Schreiber SJ, et al. Diagnostic Performance and Utility of Quantitative EEG Analyses in Delirium: Confirmatory Results From a Large Retrospective Case-Control Study. Clinical EEG and neuroscience. 2018:1550059418767584.

69. Gunther ML, Morandi A, Krauskopf E, Pandharipande P, Girard TD, Jackson JC, et al. The association between brain volumes, delirium duration, and cognitive outcomes in intensive care unit survivors: the VISIONS cohort magnetic resonance imaging study*. Critical care medicine. 2012;40(7):2022-32.

70. Morandi A, Rogers BP, Gunther ML, Merkle K, Pandharipande P, Girard TD, et al. The relationship between delirium duration, white matter integrity, and cognitive impairment in intensive care unit survivors as determined by diffusion tensor imaging: the VISIONS prospective cohort magnetic resonance imaging study*. Critical care medicine. 2012;40(7):2182-9.

71. Yocum GT, Gaudet JG, Teverbaugh LA, Quest DO, McCormick PC, Connolly ES, Jr., et al. Neurocognitive performance in hypertensive patients after spine surgery. Anesthesiology. 2009;110(2):254-61.

72. Urbanova BS, Schwabova JP, Magerova H, Jansky P, Markova H, Vyhnalek M, et al. Reduced Cerebrovascular Reserve Capacity as a Biomarker of Microangiopathy in Alzheimer's Disease and Mild Cognitive Impairment. J Alzheimers Dis. 2018;63(2):465-77.

73. Landau S, Stahl D. Sample size and power calculations for medical studies by simulation when closed form expressions are not available. Stat Methods Med Res. 2013;22(3):324-45.

74. Jenkinson M, Beckmann CF, Behrens TE, Woolrich MW, Smith SM. Fsl. Neurolmage. 2012;62(2):78290.

75. Wahlund LO, Barkhof F, Fazekas F, Bronge L, Augustin M, Sjogren M, et al. A new rating scale for agerelated white matter changes applicable to MRI and CT. Stroke. 2001;32(6):1318-22.

76. Antonenko D, Schubert F, Bohm F, Ittermann B, Aydin S, Hayek D, et al. tDCS-Induced Modulation of GABA Levels and Resting-State Functional Connectivity in Older Adults. The Journal of neuroscience : the 
official journal of the Society for Neuroscience. 2017;37(15):4065-73.

77. Young JWS. The network model of delirium. Medical hypotheses. 2017;104:80-5.

78. U.S. National Library of Medicine. ClinicalTrials.gov 2018 [updated 31.07.2018. Available from: https://clinicaltrials.gov/ct2/results?cond=spine+surgery+delirium\&term=\&cntry=\&state=\&city=\&dist=.

79. De J, Wand AP. Delirium Screening: A Systematic Review of Delirium Screening Tools in Hospitalized Patients. The Gerontologist. 2015;55(6):1079-99.

80. de Lange E, Verhaak PF, van der Meer K. Prevalence, presentation and prognosis of delirium in older people in the population, at home and in long term care: a review. International journal of geriatric psychiatry. 2013;28(2):127-34.

81. Harwood RH, Teale E. Where next for delirium research? International journal of geriatric psychiatry. 2017.

82. Shafi MM, Santarnecchi E, Fong TG, Jones RN, Marcantonio ER, Pascual-Leone A, et al. Advancing the Neurophysiological Understanding of Delirium. Journal of the American Geriatrics Society. 2017.

83. Vutskits L, Xie Z. Lasting impact of general anaesthesia on the brain: mechanisms and relevance. Nature reviews Neuroscience. 2016;17(11):705-17.

84. Siddiqi N, Harrison JK, Clegg A, Teale EA, Young J, Taylor J, et al. Interventions for preventing delirium in hospitalised non-ICU patients. The Cochrane database of systematic reviews. 2016;3:CD 005563.

85. Radtke FM, Franck M, Lendner J, Kruger S, Wernecke KD, Spies CD. Monitoring depth of anaesthesia in a randomized trial decreases the rate of postoperative delirium but not postoperative cognitive dysfunction. British journal of anaesthesia. 2013;110 Suppl 1:i98-105.

86. laccarino HF, Singer AC, Martorell AJ, Rudenko A, Gao F, Gillingham TZ, et al. Gamma frequency entrainment attenuates amyloid load and modifies microglia. Nature. 2016;540(7632):230-5.

87. Whittington RA, Virag L, Marcouiller F, Papon MA, El Khoury NB, Julien C, et al. Propofol directly increases tau phosphorylation. PloS one. 2011;6(1):e16648.

88. Dong Y, Zhang G, Zhang B, Moir RD, Xia W, Marcantonio ER, et al. The common inhalational anesthetic sevoflurane induces apoptosis and increases beta-amyloid protein levels. Archives of neurology. 2009;66(5):620-31.

89. Fodale V, Quattrone D, Trecroci C, Caminiti V, Santamaria LB. Alzheimer's disease and anaesthesia: implications for the central cholinergic system. British journal of anaesthesia. 2006;97(4):445-52.

90. van Gool WA, van de Beek D, Eikelenboom P. Systemic infection and delirium: when cytokines and acetylcholine collide. Lancet. 2010;375(9716):773-5. 
91. Berger M, Nadler JW, Friedman A, McDonagh DL, Bennett ER, Cooter M, et al. The Effect of Propofol Versus Isoflurane Anesthesia on Human Cerebrospinal Fluid Markers of Alzheimer's Disease: Results of a Randomized Trial. J Alzheimers Dis. 2016;52(4):1299-310.

92. Miller D, Lewis SR, Pritchard MW, Schofield-Robinson OJ, Shelton CL, Alderson P, et al. Intravenous versus inhalational maintenance of anaesthesia for postoperative cognitive outcomes in elderly people undergoing non-cardiac surgery. The Cochrane database of systematic reviews. 2018;8:CD012317.

93. Savio LEB, Andrade MGJ, de Andrade Mello P, Santana PT, Moreira-Souza ACA, Kolling J, et al. P2X7 Receptor Signaling Contributes to Sepsis-Associated Brain Dysfunction. Mol Neurobiol. 2017;54(8):645970 .

94. Zhang MD, Barde S, Yang T, Lei B, Eriksson LI, Mathew JP, et al. Orthopedic surgery modulates neuropeptides and BDNF expression at the spinal and hippocampal levels. Proceedings of the National Academy of Sciences of the United States of America. 2016;113(43):E6686-E95.

95. Hughes CG, Patel MB, Brummel NE, Thompson JL, McNeil JB, Pandharipande PP, et al. Relationships between markers of neurologic and endothelial injury during critical illness and long-term cognitive impairment and disability. Intensive care medicine. 2018;44(3):345-55.

96. Simons KS, van den Boogaard M, Hendriksen E, Gerretsen J, van der Hoeven JG, Pickkers P, et al. Temporal biomarker profiles and their association with ICU acquired delirium: a cohort study. Crit Care. 2018;22(1):137.

97. Beloosesky Y, Hendel D, Weiss A, Hershkovitz A, Grinblat J, Pirotsky A, et al. Cytokines and C-reactive protein production in hip-fracture-operated elderly patients. The journals of gerontology Series $A$, Biological sciences and medical sciences. 2007;62(4):420-6.

98. Diegeler A, Doll N, Rauch T, Haberer D, Walther T, Falk V, et al. Humoral immune response during coronary artery bypass grafting: A comparison of limited approach, "off-pump" technique, and conventional cardiopulmonary bypass. Circulation. 2000;102(19 Suppl 3):III95-100.

99. Holmes C, Cunningham C, Zotova E, Woolford J, Dean C, Kerr S, et al. Systemic inflammation and disease progression in Alzheimer disease. Neurology. 2009;73(10):768-74.

100. Breder CD, Dinarello CA, Saper CB. Interleukin-1 immunoreactive innervation of the human hypothalamus. Science. 1988;240(4850):321-4.

101. Banks WA, Kastin AJ. Blood to brain transport of interleukin links the immune and central nervous systems. Life Sci. 1991;48(25):PL117-21.

102. Watkins LR, Wiertelak EP, Furness LE, Maier SF. Illness-induced hyperalgesia is mediated by spinal neuropeptides and excitatory amino acids. Brain research. 1994;664(1-2):17-24. 
103. Bluthe RM, Walter V, Parnet P, Laye S, Lestage J, Verrier D, et al. Lipopolysaccharide induces sickness behaviour in rats by a vagal mediated mechanism. C R Acad Sci III. 1994;317(6):499-503.

104. Yang S, Gu C, Mandeville ET, Dong Y, Esposito E, Zhang Y, et al. Anesthesia and Surgery Impair Blood-Brain Barrier and Cognitive Function in Mice. Front Immunol. 2017;8:902.

105. Otomo S, Maekawa K, Goto T, Baba T, Yoshitake A. Pre-existing cerebral infarcts as a risk factor for delirium after coronary artery bypass graft surgery. Interact Cardiovasc Thorac Surg. 2013;17(5):799-804.

106. Omiya H, Yoshitani K, Yamada N, Kubota Y, Takahashi K, Kobayashi J, et al. Preoperative brain magnetic resonance imaging and postoperative delirium after off-pump coronary artery bypass grafting: a prospective cohort study. Can J Anaesth. 2015.

107. Reade MC, Finfer S. Sedation and delirium in the intensive care unit. The New England journal of medicine. 2014;370(5):444-54.

108. Cavallari M, Hshieh TT, Guttmann CR, Ngo LH, Meier DS, Schmitt EM, et al. Brain atrophy and whitematter hyperintensities are not significantly associated with incidence and severity of postoperative delirium in older persons without dementia. Neurobiology of aging. 2015.

109. Kant IMJ, de Bresser J, van Montfort SJT, Slooter AJC, Hendrikse J. MRI Markers of Neurodegenerative and Neurovascular Changes in Relation to Postoperative Delirium and Postoperative Cognitive Decline. The American journal of geriatric psychiatry : official journal of the American Association for Geriatric Psychiatry. 2017;25(10):1048-61.

110. Brown CHt, Faigle R, Klinker L, Bahouth M, Max L, LaFlam A, et al. The Association of Brain MRI Characteristics and Postoperative Delirium in Cardiac Surgery Patients. Clinical therapeutics. 2015;37(12):2686-99 e9.

111. Neuner B, Hadzidiakos D, Bettelli G. Pre- and postoperative management of risk factors for postoperative delirium: who is in charge and what is its essence? Aging Clin Exp Res. 2018;30(3):245-8.

112. Cizginer S, Marcantonio E, Vasunilashorn S, Pascual-Leone A, Shafi M, Schmitt EM, et al. The Cognitive Reserve Model in the Development of Delirium: The Successful Aging After Elective Surgery Study. Journal of geriatric psychiatry and neurology. 2017;30(6):337-45.

113. Franzmeier N, Duzel E, Jessen F, Buerger K, Levin J, Duering M, et al. Left frontal hub connectivity delays cognitive impairment in autosomal-dominant and sporadic Alzheimer's disease. Brain. 2018;141(4):1186-200.

114. Choi SH, Lee H, Chung TS, Park KM, Jung YC, Kim SI, et al. Neural network functional connectivity during and after an episode of delirium. The American journal of psychiatry. 2012;169(5):498-507. 
115. Huang H, Tanner J, Parvataneni H, Rice M, Horgas A, Ding M, et al. Impact of Total Knee Arthroplasty with General Anesthesia on Brain Networks: Cognitive Efficiency and Ventricular Volume Predict Functional Connectivity Decline in Older Adults. J Alzheimers Dis. 2018;62(1):319-33.

116. Browndyke JN, Berger M, Harshbarger TB, Smith PJ, White W, Bisanar TL, et al. Resting-State Functional Connectivity and Cognition After Major Cardiac Surgery in Older Adults without Preoperative Cognitive Impairment: Preliminary Findings. Journal of the American Geriatrics Society. 2017;65(1):e6e12.

117. Aranake-Chrisinger A, Avidan MS. Postoperative delirium portends descent to dementia. British journal of anaesthesia. 2017;119(2):285-8.

118. Murkin JM, Newman SP, Stump DA, Blumenthal JA. Statement of consensus on assessment of neurobehavioral outcomes after cardiac surgery. Ann Thorac Surg. 1995;59(5):1289-95.

119. Brown CHt, Probert J, Healy R, Parish M, Nomura Y, Yamaguchi A, et al. Cognitive Decline after Delirium in Patients Undergoing Cardiac Surgery. Anesthesiology. 2018;129(3):406-16.

\section{Table 1. Summary Of The Recruitment Process And Visit Plan According To The Standard Protocol Items: Recommendations For Interventional Trials (Spirit) Checklist. \\ Supplementary Files}

This is a list of supplementary files associated with this preprint. Click to download.

- supplement1.docx 


\begin{tabular}{|c|c|c|c|c|c|c|c|c|c|c|}
\hline & \multirow{3}{*}{$\begin{array}{l}\text { enrol- } \\
\text { ment }\end{array}$} & \multicolumn{9}{|c|}{ STUDY PERIOD } \\
\hline & & $\begin{array}{c}\text { pre- } \\
\text { operative }\end{array}$ & $\begin{array}{c}\text { intra- } \\
\text { operative }\end{array}$ & \multicolumn{5}{|c|}{ postoperative } & \multirow{2}{*}{$\begin{array}{c}\text { 3- } \\
\text { month } \\
\text { follow- } \\
\text { up } \\
90 d \pm 14\end{array}$} & \multirow{2}{*}{$\begin{array}{c}\begin{array}{c}\text { 1-year } \\
\text { follow-up }\end{array} \\
360 \mathrm{~d} \pm 14\end{array}$} \\
\hline TIMEPOINT & & $-7 d \pm 7$ & 0 & $1 d$ & $2 \mathrm{~d}$ & $3 \mathrm{~d}$ & $4 d$ & etc. & & \\
\hline Eligibility screen & $\mathrm{X}$ & & & & & & & & & \\
\hline Informed consent & $\mathrm{X}$ & & & & & & & & & \\
\hline Demographic data & & $\mathrm{X}$ & & & & & & & & \\
\hline Medical history & & $\bar{X}$ & & & & & & & $\mathrm{X}$ & $\mathrm{X}$ \\
\hline Cognitive testing & & $\mathrm{X}$ & & & & & & & $\mathrm{X}$ & $\mathrm{X}$ \\
\hline Quality of Life & & $\mathrm{X}$ & & & & & & & $\mathrm{X}$ & \\
\hline Activities of daily living & & $\mathrm{X}$ & & & & & & & $\mathrm{X}$ & \\
\hline Bispectral index monitoring & & & $\mathrm{X}$ & & & & & & $\mathrm{X}$ & \\
\hline Vital parameters & & & $\mathrm{X}$ & & & & & & & \\
\hline Delirium & & $\mathrm{X}$ & & $\mathrm{X}$ & $\mathrm{X}$ & $\mathrm{X}$ & $X$ & $X$ & & \\
\hline Medication & & $\mathrm{X}$ & $\mathrm{X}$ & $\mathrm{X}$ & $\mathrm{X}$ & $\mathrm{X}$ & $\mathrm{X}$ & $\mathrm{X}$ & $\mathrm{X}$ & $\mathrm{X}$ \\
\hline Pain & & $\mathrm{X}$ & & $\mathrm{X}$ & $\mathrm{X}$ & $\mathrm{X}$ & $\mathrm{X}$ & $\mathrm{X}$ & & \\
\hline Mobilization & & & & $\mathrm{X}$ & $\mathrm{X}$ & $\mathrm{X}$ & $\mathrm{X}$ & $\mathrm{X}$ & & \\
\hline sMRI/rs-fMRI & & $\mathrm{X}$ & & & & & & & $\mathrm{X}$ & \\
\hline Cerebrovascular ultrasound & & $\mathrm{X}$ & & & & & & & & \\
\hline Inflammatory markers & & $\mathrm{X}$ & $\mathrm{X}$ & $\mathrm{X}$ & $\mathrm{X}$ & & & & & \\
\hline Neural injury markers & & $\mathrm{X}$ & $\mathrm{X}$ & $\mathrm{X}$ & $\mathrm{X}$ & & & & & \\
\hline $\begin{array}{l}\text { brain-derived neurotropic } \\
\text { factor polymorphism }\end{array}$ & & $\mathrm{X}$ & & & & & & & & \\
\hline
\end{tabular}

